\title{
Elements contributing to the environ-urban dimension of a smart city concept
}

\author{
Anastasiia Sedova $^{1 *}$ and Alevtina Balakina $^{2}$ \\ ${ }^{1}$ Kalashnikov Izhevsk State Technical University, Department of Architecture, Studencheskaya str. 7, \\ Izhevsk, Russia \\ ${ }^{2}$ Moscow State University of Civil Engineering, Yaroslavskoe shosse, 26, Moscow, 129337, Russia
}

\begin{abstract}
Smart city concept concerns urban innovations based on but not limited by the wide application of IoT. Whereas, four dimensions encompass various elements of smart cities: governance dimension, environ-urban dimension, socio-institutional dimension, and techno-economic. The research focuses on the score of factors contributing to the environ-urban dimension. Based on the previous research of the authors, where the elements of the studied dimension were listed according to their importance, this paper uses QCA methodology in order to understand which elements should be proceeded first among the element of similar high importance when driving cities to the smart development. Fourteen cities in which smart practices are being realised, were retrieved among a top hundred cities around the globe from the heatmap which shows the places people like the most. The paper concludes with the recommendations what elements are able to fill environ-urban dimension effectively, that can support cities which have recently started the way to the smart city concept.
\end{abstract}

\section{Introduction}

In $2018,55 \%$ of the worlds population lived in urban areas, a proportion that is expected to increase to $68 \%$ by 2050 [1]. Despite of the fact that living in cities provide challenges and disadvantages associated with growing urban agglomerations, the world population has been concentrating in cities [2]. The continuous growth of urban areas of many cities across the globe is a predictable results of such process. This has been made possible by an application of newest urban technologies, urban design and planning, partnerships between relevant stakeholders, etc. As a result, the concept of a smart city emerged. In a scientific world a smart city concept is acknowledged as a driver for urban innovation, that could address the rapid growth of urban areas and increase the quality of living cities [2, 3].

In the recent scientific literature, the smart city concept in associated with a number of key words. Smart citizen, smart governance, smart technology and mobility, and smart tools are four aggregation groups which fill the smartness of today's cities [4]. In this devision smart people and technology ensure better living, while smart governance and economy

\footnotetext{
*Corresponding author: sedovaanastasiia@yandex.com
} 
ensure smart environment. To summarise, the driving cities towards smartness aims to make urban areas a high-quality place.

When searching for pillars of the smartness, we discover that scientist point out four dimensions: governance dimension, environ-urban dimension, socio-institutional dimension, and techno- economic dimension [5]. The environ-urban dimension is composed but not limited to the following elements: the built infrastructure, smart mobility [6], urban design [7], facilities and amenities, and natural environment [8, 9]. In other words, this dimension focuses on how to improve liability of cities with the means of urban planning and design. Bibri and Krogstie wrote that urban planning is "the process of guiding and directing the use and development of land, urban environment, urban infrastructure, and related ecosystem and human services - in ways that ensure the maximum level of economic development, high quality of life, wise management of natural resources, and efficient operation of infrastructures" [10], while urban design is a multidisciplinary field involving architects, urban planners and civil engineers. In a smart city practice, urban design entails connecting different factors with each other, such as built-up environment and natural environment, architectural forms for human settlements and the aspects of smart development, liability and quality, etc. [10]. Thus, the way cities designed, planned and function is of importance for smart development.

The environ-urban branch of a smart city research links up with the concept of smart urban design, where the creation of innovation districts, living labs infrastructure, smart mobility, leisure amenities and facilities, and the use of vernacular solutions are the key performance factors [5]. In the previous research paper of the authors, twenty-four elements which contribute positively to the filling of the environ-urban dimension of the smart city concept were identified [11]. The elements were identified on the basis of architectural proposals for future urban regeneration projects. Seven out of twenty-four elements has high equal importance for the smart city concept delivery: preservation of natural environment, legible public realm, accessible public spaces, shared public spaces, public green infrastructure, walkable neighbourhood, the promotion of sustainable habits. In the present research paper authors aim to answer on the following question: What element(s) among the above seven identified should be considered first and addressed earlier than others when driving to the smart city?

Today, smart city lacks a shared definition [10], and hence, it is challenging to identify common trends when answering the raised question. To overcome this difficultly, the research studies smart practices in fourteen cities from all around the globe in order to formulate an objective vision when answering the research question.

\section{Research design and methodology}

Based on the elements highlighted in the introduction, a qualitative research is carried out in order to investigate the essential factors at the environ-urban dimension of the smart cities' international practice. The authors focuses on a case study approach because it is generally considered more suitable for in-depth investigation of a research question [12]. The case studies are selected to fulfil the idea of representativeness of local smart urban planning and design projects in Europe, the USA, China, Australia, and Asia.

At the first stage the authors searched for smart practices in different cities. Despite of the fact that cities are shaped by the differences in culture, vernacularity, history, people's behaviour, natural environment, etc., the smart solutions in each city aim the creation of high quality place of living [4].

Making city "lively" and "vibrant" are the essential principles to make a high-quality place [13]. In this sense "lively" and "vibrant" are the principal characteristics of a growing city which is able to offer comfortable environment for citizens and being attractive for 
tourists. The authors argue that the use of social media check-ins could contribute in understanding how "lively" and "vibrant" different cities are. Fourteen cities with high numbers of check-ins are chosen for studying of smart solutions. The trustable source is used for the cities retrieval: the Sightsmap, is a heatmap showing the most and least heat world cities according to social media check-ins. The heat map shows the places people like, based on the quantity of photos geotagged at each place in the world. The hottest places have markers linking photos, streetview, wikipedia, wikivoyage, foursquare and google plus articles about the site [14]. Area populations are based on the geonames database [14]. The popularity ranking of places in high-res area maps is computed by combining place hotness with popularity rankings from wikipedia, foursquare and real-time google places selection [14].

The choice based on the data collected at the Sightsmap is essential to explore "lively" and "vibrant" areas, the characteristics of which are based on the valuation of different groups of people in terms of age, sex, social standing, job position, religion, income, etc. Th retrieval of cities, appreciated by different groups, benefit the search of smart practices which create high value for the society in general to further inform about the importance of such practices.

Choosing different cities is essential to explore the variety of smart practices which fill the environ-urban dimension. Undoubtedly, that the smartness vary from one city to another, while the liveability of such cities proves the success of applied smart tools and initiatives.

At the second stage the author focuses on analysing smart initiatives are being performed in each of fourteen cities. This part of the research is based of the Qualitative Comparative Analysis (QCA), a methodology designed for analyses of multiple cases in complex situations [15]. The QCA allows to identify features of smart initiatives related to seven elements of the environ-urban dimension of a smart city concept: preservation of natural environment, legible public realm, accessible public spaces, shared public spaces, public green infrastructure, walkable neighbourhood, and the promotion of sustainable habits.

The methodology for the data collection is based on the one proposed by Yin [16], which entails the triangulation of available reference sources: literature review, output analysis, and participant responses. Specifically, it was carried out a scientific literature analysis, that focuses on the identification and explanations of architectural and urban smart solutions. The major part of this analysis was published in the previous paper by the authors, Sedova and Balakina [11]. Output analysis focuses on the list of smart practices available of the platform of World practices of Smart Cities [17]. The last source, participant responses, have indirect character and presented by the data retrieved from the Sightsmap. Then the data is structured in order to answer the research question, this involves searching for the presence of each of seven environ-urban element in every smart practice case study and setting up some criteria for how it will be scored. The scoring based on the "crisp-set", developed by Ragin [15]. In this research the authors score the presence of each factor, whether it relates to tangible or intangible promotion of smartness. Tangible elements are environmental characteristics, while intangible ones - different models and ways on how people can behave, feel and interact within the city[18]. Both direct and indirect presence of the elements is considered.

After the presentation of the case studies and their smart practices, the paper analyses the datasets and interpret the findings.

\section{Results}

As previously explained, the data collection aims to answer the research question in order to understand what elements of the environ-urban dimension have higher importance, and thus should be addressed first.

Fourteen cities were chosen among the top-hundred of the most heat referring to the Sightsmap heatmap. Understanding how much people like the cities is essential to making a 
place liveable [19] and connect directly with the grade of the smartness. In order to be objective, the authors decided to retrieve several top cities, several cities from the middle of top-hundred and several cities from the end of the said ranking. The chosen cities are the following: New York (first place), Barcelona (third place), London (fifteenth place), Chicago (seventeenth place), Shanghai (eighteenth place), Hong Kong (twenty-fourth place), Tokyo (thirty-sixth place), Amsterdam (forty-fourth place), Boston (forty-fifth place), Melbourne (fifty-second place), Singapore (sixty-second place), Dubai (sixty-seventh place), SaintPetersburg (ninety-sixth place), and Moscow (ninety-eighth place) [14].

The number of smart practices being performed in these cities vary from 3 to 77 . The smart practices and initiatives were published at the map of World practices in Smart City [17], those of them related to the environ-urban dimension are listed below:

- New York: Expansion of Green Infrastructure Program, Climate Action Challenge, NYC as a Smart City Testbed, First Dockless Bikes, Love your Block, Competition for the development of affordable housing technologies, Expansion Of Citi Bike, Urban innovation community [17].

- Barcelona: Smou app, New Biking system, Centre for technological waste management, A digital manufacturing and learning centre [17].

- London: Refill London, Bold Strategy for the Future of London's Transport, New taskforce to expand electric vehicle infrastructure, Homes for Londoners, Interactive streetside hubs, A 'live hub' of planning and development information, Action plan for cycling, Scrappage scheme for most polluting vans, Low Emission Bus Zones [17].

- Chicago: Major increase in accessible pedestrian signals at intersections across Chicago, Next Phase of Chicago Smart Lighting Program, Garfield Green project, New Transportation and Mobility Task Force, Streetlight Modernization Program [17].

- Shanghai: Automated metro at Shanghai Pudong airport, LED for historic objects [17].

- Hong Kong: Smart street infrastructure, HKeMobility [17].

- Tokyo: Digital information tables for tourisits, Tourist Information Maps Using Digital Signage, Tokyo Subway Ticket [17].

- Amsterdam: RESILIO - Amsterdam Blue Green Roofs, WarmBouwen, An interactive sketching tool for complicated urban matters, LoRa Smart Lighting + Lightwell Dutch Design Friso Kramer LED, Green City Buzz, My Clean City, Roboat, Flexpower [17].

- Boston: Ride-sharing zone [17].

- Melbourne: Transport Strategy to 2050, Waste management strategy 2030, New Melbourne Visitor Hub [17].

- Singapore: Land Transport Industry Transformation Map, Airbitat Oasis Smart Bus Stop, Land Transport Master Plan 2040, Unmanned Digital Kiosks [17].

- Dubai: Waste-to-energy plant, Smart system to reduce transport waiting times during large events [17].

- Saint-Petersburg: Smart lighting at pedestrian crossings, Talking City System [17].

- Moscow: Moscow car-sharing, Interactive museum guide, VeloBike, Moscow parking, Smart quarter [17].

The listed smart initiatives are analysed according to how much they fulfill any of the elements of the environ-urban smart city dimension: A - Preservation of natural environment; B - Legible public realm; C - Accessible public spaces; D - Shared public spaces; E - Public green infrastructure; F - Walkable neighbourhood; G - Promotion of sustainable habits. Using such criteria, the qualitative data for each element in each city case study is converted into a score. According the the QCA methodology, the score can be " 0 " or " 1 " [15], " 0 " means an absence of an element in a case study, while "1" a presence of an element in a smart city practice. This score is created for all initiatives in each single smart city taken together. The results of the score is presented in Table 1. 
Table 1. Score of the environ-urban dimension elements and international smart practices.

\begin{tabular}{|l|c|c|c|c|c|c|c|}
\hline & A & B & C & D & E & F & G \\
\hline New York & 1 & 1 & 0 & 1 & 0 & 1 & 1 \\
\hline Barcelona & 1 & 1 & 1 & 1 & 0 & 0 & 1 \\
\hline London & 0 & 1 & 0 & 0 & 0 & 0 & 1 \\
\hline Chicago & 0 & 0 & 1 & 0 & 0 & 1 & 1 \\
\hline Shanghai & 0 & 0 & 0 & 0 & 0 & 0 & 1 \\
\hline Hong Kong & 0 & 1 & 0 & 0 & 0 & 0 & 0 \\
\hline Tokyo & 0 & 1 & 0 & 0 & 0 & 0 & 0 \\
\hline Amsterdam & 1 & 1 & 1 & 0 & 1 & 0 & 1 \\
\hline Boston & 0 & 1 & 0 & 0 & 0 & 0 & 0 \\
\hline Melbourne & 0 & 1 & 0 & 0 & 0 & 0 & 1 \\
\hline Singapore & 0 & 1 & 0 & 0 & 0 & 0 & 0 \\
\hline Dubai & 0 & 1 & 0 & 0 & 0 & 0 & 1 \\
\hline St. Petersburg & 0 & 1 & 0 & 0 & 0 & 0 & 0 \\
\hline Moscow & 0 & 1 & 0 & 1 & 0 & 0 & 0 \\
\hline & $3 / 14$ & $12 / 14$ & $3 / 14$ & $3 / 14$ & $1 / 14$ & $2 / 14$ & $8 / 14$ \\
\hline
\end{tabular}

The score presented in Table 1 shows that element B - Legible public realm in the most important element which fulfil the environ-urban dimension of a smart city concept. Twelve out of fourteen cities are currently implementing initiatives which make these cities more legible, comfortable and liveable. Thus, this element should be addressed first when "filling" the smart city concept by the means of urban planning and urban design.

Element $\mathrm{G}$ - Promotion of sustainable habits is less important than element B but still create value of the smartness of cities.

Elements A, C, D have equal low scores, this means the lower smart input of such element. Elements $\mathrm{E}$ and $\mathrm{F}$ are the least important elements of the environ-urban dimension.

\section{Discussion}

This research paper proved the fact that smart city should offer legible public realm and highquality living conditions to its citizens, the fact pointed out by Camboim et al. [5]. The second element, promotion of sustainable habits, can be seen as a mean helping in the creation of liveable urban environment. This proves the need to mention a newest phenomenon - "smart sustainable city". Bibri and Krogstie wrote that a smart sustainable city is associated with massive use of advanced ICT, which enhance various elements of a smart city concept and pillars of sustainable development [10]. Urban areas are created to become legible with the application of both traditional (urban planning and design) and contemporary (overwhelming digitalisation, synthesis of data involving facilities, infrastructure, citizens) methods. Bibri 
and Krogstie argued that ICT is a critical driver the success of environmental smart solutions [10]. It is safe to assume, that the least scored factors should be considered as potential elements for ICT application rather than only as a mean of urban design. In this way the the use of ICT increases value of traditional urban solutions.

\section{Conclusion}

Answering the research question raised at the introduction of this paper, two elements have major importance when driving to the smart city destination: the creation of legible public realm and promotion of sustainable habits. These elements can fill the environ-urban dimension with a greater success. The authors proposed that these elements should be addressed first.

The results of the research shows that terms "smart city" and "sustainable city" have many elements in common. The authors suggest, that the development of urban areas based on urban growth, technological development, the creation of liveable and vibrant high-quality place should be labelled "smart sustainable" rather than only "smart" or "sustainable". To summarise, the aspects of sustainable development can enhance the concept of smart development increasing smartness and liveability of urban areas by the means of urban planning and design.

\section{References}

1. United Nations, World Urbanization Prospects: The 2018 Revision, Available from: https://population.un.org/wup/Publications/Files/WUP2018-KeyFacts.pdf [Accessed 8 July 2019] (2018)

2. A. Caragliu, C. Del Bo, P. Nijkamp, Smart Cities in Europe, Journal of Urban Technology, 18, 2, pp. 65-82 (2011)

3. J. Fredericks, L. Hespanhol, C. Parker, D. Zhou, M. Tomitsch, Blending pop-up urbanism and participatory technologies: Challenges and opportunities for inclusive city making, City, Culture and Society, 12, pp 44-53 (2018)

4. H. Abusaada, A. Elshater, Competitiveness, distinctiveness and singularity in urban design: A systematic review and framework for smart cities, Sustainable Cities and Society, 68, 102782 (2021)

5. G. F. Camboim, P. A. Zawislak, N. A. Pufal, Driving elements to make cities smarter: Evidences from European projects, Technological Forecasting \& Social Change, 142, pp. 154-167 (2019)

6. B. Mattoni, F. Gugliermetti, F. Bisegna, A multilevel method to assess and design the renovation and integration of smart cities, Sustainable Cities and Society, 15, pp. 105119 (2015)

7. S. I. Chiodi, Crime prevention through urban design and planning in the smart city era: the challenge of disseminating CP-UDP in Italy: learning from Europe, Journal of Place Management and Development, 9, 2, pp. 137-152 (2016)

8. J. R. Gil-Garcia, T. A. Pardo, T. Nam, What makes a city smart? Identifying core components and proposing an integrative and comprehensive conceptualization, Information Policy, 20, 1, pp. 61-87 (2015)

9. F. Bifulco, M. Tregua, C. C. Amitrano, A. D'Auria, ICT and sustainability in smart cities management, International Journal of Public Sector Management, 29, 2, pp. 132-147 (2016) 
10. S. E. Bibri, J. Krogstie, Smart sustainable cities in the future: An extensive interdisciplinary literature review, Sustainable Cities and Society, 31, pp. 183-212, (2017).

11. A. Sedova, A. Balakina, Reinventing cities towards being smarter, IOP Conference Series: Materials Science and Engineering, 865, 022023 (2020)

12. M. Q. Patton, Qualitative evaluation and research methods (3rd ed.), Thousand Oaks, CA: Sage (2002)

13. W. H. Whyte, The social life of small urban spaces, Public Spaces (1980)

14. Sightsmap, Available from: http://www.sightsmap.com [Accessed 27 February 2021] (2021)

15. C. Ragin, What is Qualitative Comparative Analysis (QCA)?, Available at: $\mathrm{http} / /$ eprints.ncrm.ac.uk/250/1/What_is_QCA.pdf (1984)

16. R. K. Yin, Case study research and applications, Thousand Oaks, CA: Sage (2018)

17. World practices of Smart Cities, Available from: https://ict.moscow/projects/smart-cities/ [Accessed 27 February 2021] (2021)

18. M. Mazzarello, C. Ratti, Leveraging the Use of Digital Technologies to Activate Public Areas and Foster Creativity, in M. I. Aldinhas Ferreira (ed.) How smart is your city?, Springer, (2021)

19. F. Zhang, J. Zu, M. Hu, D. Zhu, Y. Kang, S. Gao, Y. Zhang, Z. Huang, Uncovering inconspicuous places using social media check-ins and street view images, Computers, Environment and Urban Systems, 81, 101478, (2020) 